ORIGINAL ARTICLE

\title{
When does mother to child transmission of hepatitis $C$ virus occur?
}

\author{
J Mok, L Pembrey, P-A Tovo, M-L Newell, for the European Paediatric Hepatitis C Virus Network
}

Arch Dis Child Fetal Neonatal Ed 2005;90:F156-F160. doi: 10.1136/adc.2004.059436

See end of article for authors' affiliations

....................

Correspondence to: Professor Newell, Centre for Paediatric Epidemiology \& Biostatistics Institute of Child Health (University College London), 30 Guilford Street, London WCIN 1EH, UK m.newell@ich.udl.ac.uk

Accepted 15 October 2004

\begin{abstract}
Objective: To investigate when hepatitis $\mathrm{C}$ virus $(\mathrm{HCV})$ infection from mother to child occurs, and evaluate possible associated factors.

Design: Prospective cohort study.

Patients: Fifty four HCV infected children tested within three days of birth and their mothers.

Main outcome measures: HCV RNA polymerase chain reaction (PCR) results.

Results: Seventeen of the children (31\%, 95\% confidence interval 19\% to $46 \%$ ) were positive in the first 3 days of life and could be assumed to have acquired infection in utero. Testing PCR positive was not associated with sex $(53 \%$ v $49 \%$ boys; $p=0.77)$ or mode of delivery $(29 \%$ elective caesarean section in both groups; $p=0.98$ ). Children with evidence of intrauterine infection were significantly more likely to be of lower birth weight and infected with genotype 1 (58\% v 12\%, p = 0.01). Although a higher proportion of infants born to HCV/HIV co-infected women were PCR positive in the first 3 days of life, this difference did not reach statistical significance; excluding infants born to co-infected women did not affect the results. Thirty seven of the children (68\%) were negative in the first 3 days of life, 27 of whom were positive when tested again at 3 months, and nine were first PCR positive after 3 months (one child had no further tests). Conclusions: These results suggest that at least one third and up to a half of infected children acquired infection in utero. Although postpartum transmission cannot be excluded, these data suggest that it is rare. The role of $\mathrm{HCV}$ genotypes in the timing and mechanism of infection should be explored further.
\end{abstract}

$\mathrm{T}$ he overall rate of mother to child transmission of hepatitis C virus (HCV) infection is $4-10 \% .{ }^{1-7}$ Maternal HIV coinfection has been associated with up to a fourfold increase in HCV transmission, ${ }^{1267}$ and women with HCV viraemia are more likely to transmit than non-viraemic women. ${ }^{8-11}$ Transmission through breast feeding is assumed to be rare but cannot be excluded, ${ }^{12}{ }^{13}$ while the effect of mode of delivery on risk of transmission remains uncertain. ${ }^{13611}$

The exact time during pregnancy or delivery when HCV transmission occurs is unclear. Both intrauterine ${ }^{414}$ and intrapartum ${ }^{6}{ }^{11}$ infection occur, but the relative contribution by each route remain poorly quantified. Development of successful strategies to prevent mother to child transmission of HCV depends on understanding the timing of transmission, and associated factors.

The diagnosis of vertically acquired HCV infection is based on detection of viraemia (HCV RNA by polymerase chain reaction (PCR)) and/or the presence of specific non-maternal antibody, with the timing of transmission inferred from results of virus specific tests on samples drawn soon after birth when a positive result implies intrauterine infection. ${ }^{15}$

Data available within the European Paediatric Hepatitis C Network provided an opportunity to clarify when HCV infection from mother to child occurs, and to evaluate factors that may influence the timing of transmission.

\section{MATERIALS AND METHODS Study population}

The European Paediatric Hepatitis C Network, a prospective study on mother to child transmission of HCV, was established in 1998, ${ }^{7}$ with prospectively collected information also available for some infected children born in previous years. Mother-child pairs were enrolled from 31 centres in seven countries in Western Europe. Appropriate ethical approval was obtained from each centre. Data on maternal factors (HIV status, injecting drug use, HCV viraemia) were collected at enrolment and during pregnancy, and mode of delivery, birth weight, gestational age, and sex of the child were recorded at delivery. Children were followed prospectively from birth, with clinical assessments every three months. Laboratory investigations were performed locally and included serum HCV RNA, HCV antibody, and alanine aminotransferase activity. The study protocol recommends that a PCR test for HCV RNA is performed in the first three days of life and then at 6 weeks, 3, 6, 9, 12, 18, and 24 months. Data were collected on study forms and sent to the coordination centre at regular intervals.

HCV infection was diagnosed by qualitative HCV RNA PCR and antibody tests. A child was considered to be vertically infected with HCV if he/she tested positive for HCV RNA on at least two separate occasions and/or was HCV antibody positive at or beyond 18 months of age.

Intrauterine infection was assumed in infected children who tested PCR positive for HCV RNA in the first 3 days of $\operatorname{life}^{15}$ (group 1). Group 2 consisted of infected children who were PCR negative in the first 3 days. Late intrauterine infection (during the last month of pregnancy) or intrapartum transmission (occurring during delivery) could be assumed in infants who are PCR negative in the first 3 days of life but are PCR positive by 4 weeks. Peripartum transmission included late intrauterine and intrapartum infection.

\section{Data processing and statistical analysis}

Forms were checked and entered on to a Microsoft Access database. Statistical analyses were carried out using Stata 7 (Stata Corporation, College Station, Texas, USA). Odds ratios were calculated to estimate the effect of maternal, delivery, and infant factors on being PCR positive in the first 3 days of life, and $\chi^{2}$ tests were carried out where data were not sufficient to calculate an odds ratio. Mantel-Haenszel odds ratio estimates were obtained to allow for the effect of potential confounding variables.

Abbreviations: $\mathrm{HCV}$, hepatitis $\mathrm{C}$ virus; $\mathrm{PCR}$, polymerase chain reaction 
Table 1 Factors associated with being polymerase chain reaction (PCR) positive in first 3 days of life

\begin{tabular}{|c|c|c|c|c|}
\hline & Total & $\begin{array}{l}\text { No of children PCR positive } \\
\text { in first } 3 \text { days }\end{array}$ & Unadjusted odds ratio $(95 \% \mathrm{Cl})$ & p Value \\
\hline Mother HIV uninfected & 38 & $9(24 \%)$ & 1.0 & \\
\hline Mother HIV co-infected & 14 & $6(43 \%)$ & $2.42(0.64$ to 9.16$)$ & 0.18 \\
\hline Missing & 2 & 2 & & \\
\hline Mother PCR positive & 10 & $4(40 \%)$ & $\chi^{2}=2.24 \dagger$ & 0.21 \\
\hline Mother PCR negative & 4 & $0(0 \%)$ & & \\
\hline Missing & 40 & & & \\
\hline Male & 27 & $9(33 \%)$ & 1.0 & \\
\hline Female & 27 & $8(30 \%)$ & $0.84(0.26$ to 2.69$)$ & 0.77 \\
\hline Vaginal \& emergency CS & 34 & $12(35 \%)$ & 1.0 & \\
\hline Elective CS & 14 & $5(36 \%)$ & $1.02(0.27$ to 3.79$)$ & 0.98 \\
\hline Missing & 6 & 0 & & \\
\hline Normal birth weight & 38 & $13(34 \%)$ & $\chi^{2}=3.51 \dagger$ & 0.13 \\
\hline Low birth weight $(<2500 \mathrm{~g})$ & 2 & $2(100 \%)$ & & \\
\hline Missing & 14 & 2 & & \\
\hline Term* & 24 & $8(33 \%)$ & $\chi^{2}=3.47 \dagger$ & 0.14 \\
\hline Premature $^{*}$ (<37 weeks) & 2 & $2(100 \%)$ & & \\
\hline Missing & 28 & 7 & & \\
\hline Formula fed & 39 & 15 (38\%) & 1.0 & \\
\hline Breast fed & 11 & $1(9 \%)$ & $0.16(0.02$ to 1.52$)$ & 0.07 \\
\hline Missing & 4 & 1 & & \\
\hline Genotype 2, 3, 4 & 16 & $2(12 \%)$ & 1.0 & \\
\hline Genotype 1 & 12 & $7(58 \%)$ & 9.80 (1.10 to 86.98$)$ & 0.01 \\
\hline Missing & 26 & 8 & & \\
\hline
\end{tabular}

\section{RESULTS}

Overall, 290 vertically exposed children met the criteria for HCV infection. Of these, 54 had a PCR test performed in the first 3 days of life; 17 (31\%, 95\% confidence interval (CI) 19\% to $46 \%$ ) were positive, and $37(68 \%)$ were negative.

\section{Factors associated with being PCR positive in first 3 days of life}

Clinical and virological characteristics were compared between children who were PCR positive in the first 3 days of life (group 1) and those who were PCR negative in the first 3 days of life (group 2) (table 1). A higher proportion of infants born to HIV co-infected women were PCR positive in the first 3 days of life than infants born to women with only HCV infection, but this difference was not statistically significant. Mode of delivery and sex were not associated with being PCR positive in the first 3 days of life. Median gestational age was 39 weeks in each group and ranged from 33 to 41 weeks among infants in group 1 and from 34 to 41 weeks among group 2 infants. Although mean birth weight was significantly lower among the children with evidence of intrauterine infection (2976 g (range 1820-3900) v $3327 \mathrm{~g}$ (range 2520-4840) $)$ in the group 2 children $(t$ (two sided) $=$ $-2.09, \mathrm{p}=0.04)$, a significant difference was not observed when low birthweight infants $(<2500 \mathrm{~g})$ were compared with normal weight infants (table 1). Breast fed infants were less likely to be PCR positive in the first 3 days of life than formula fed infants, although this association was of borderline significance because of the small numbers involved. Infants infected with HCV genotype 1 were significantly more likely to be PCR positive in the first 3 days of life than infants infected with other HCV genotypes $(2,3$, or 4$)$.

Fourteen mothers had at least one HCV PCR test available during pregnancy or around the time of delivery (median time of testing four weeks before delivery, range 30 weeks before delivery to 1.9 months postpartum). Four (40\%) of 10 infants born to PCR positive women were themselves PCR positive in the first 3 days of life compared with none of four infants born to PCR negative women (table 1). The difference was not significant because of the small numbers involved, but suggests that women who are viraemic during pregnancy may be more likely to transmit HCV before delivery.

Univariable odds ratios for the effect of sex, mode of delivery, low birth weight, prematurity, infant feeding, genotype, and maternal viraemia on being PCR positive in the first 3 days were calculated separately for infants born to women with only HCV infection and were similar to the overall results.

It was not appropriate to perform a multivariable analysis with only 54 children, but bivariable odds ratios were calculated (adjusting for one factor at a time) where possible. None of the adjusted odds ratios for mode of delivery differed substantially from the unadjusted estimate. Although the odds ratio for the effect of maternal HIV infection increased from 2.42 to 7.50 (95\% CI 0.43 to $130.87, \mathrm{p}=0.10$ ) when allowing for genotype, it still did not reach significance and the confidence interval was very wide.

The positive association between genotype 1 and being PCR positive in the first 3 days of life remained significant when adjusted for mode of delivery, sex, or maternal HIV infection, but with wide confidence intervals (respective adjusted ORs and p values: 6.90 and $0.02 ; 8.33$ and $0.01 ; 14.00$ and 0.008 ). However, when maternal viraemia was allowed for, the odds ratio for the effect of genotype decreased substantially and was no longer significant (adjusted OR 1.33, 95\% CI 0.05 to 32.96, $\mathrm{p}=0.86$ ), which reflects the fact that genotype was only available for infants of viraemic women. 

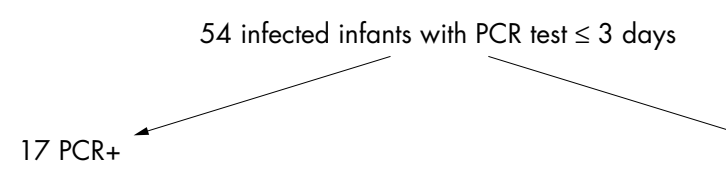

( $31 \%$ in utero transmission)
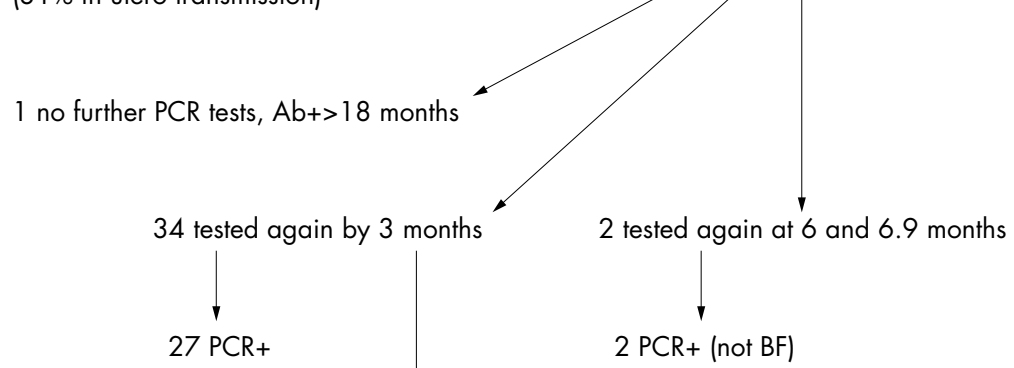

Figure 1 Timing and results of PCR tests in infected infants. Ab, antibody; $\mathrm{BF}$, breast fed; PCR, polymerase chain reaction. i.e. late intrauterine, intrapartum)

Includes child 2 (BF),

3 (BF), 4 (BF), 5 (BF)

and 8 from table 2 .

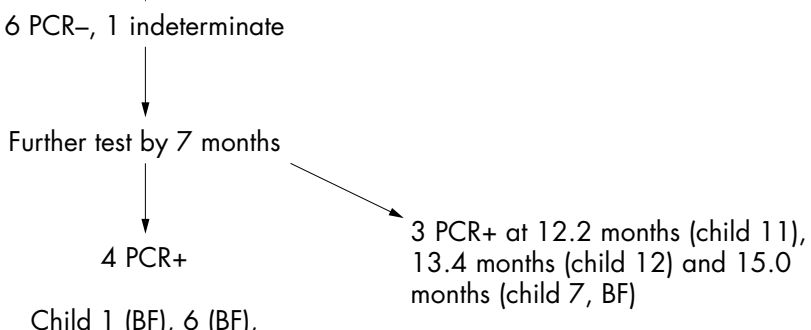

Child 1 (BF), 6 (BF),

9 and 10 from table 2 .

(17\% peripartum transmission)

\section{Infants PCR negative at birth (group 2)}

One of the 37 infants who were negative in the first 3 days of life had no subsequent PCR test results available but was considered infected on the basis of positive antibody tests beyond 18 months. Among the other 36 infants, the mean age at first positive PCR was 3.9 months (median 3.0 months, range 12 days-15 months). After the initial negative PCR result, 34 of 36 were tested again by 3 months of age, and 27 were positive (fig 1). The remaining two had their second PCR tests at 6 and 7 months. Of all 36 infants, 33 were PCR positive by 7 months of age. The remaining three became PCR positive at 12.2, 13.4, and 15.0 months of age. Of these three infants, one was breast fed until 12 weeks, and two were not breast fed.

Timing of infection was difficult to estimate for 12 group 2 infants who had late first positive PCR tests and were either breast fed or had late last negative PCRs (table 2). Seven of 12 infants were breast fed, suggesting possible postnatal transmission through breast milk. However, in five of these seven, the last negative PCR was very early ( $\leqslant 3$ days). They may have become PCR positive by 4 weeks (and intrapartum transmission therefore possible), but were not tested again until at least 3 months. Of the 24 group 2 infants who were not breast fed, 19 were PCR positive when next tested (between 26 days and 6.9 months). The remaining five tested negative at least once again before testing positive at between 2.2 and 13.4 months and were negative after 4 weeks of age (table 2). These five children had a similar pattern of PCR results to the seven breastfed children, indicating that these viraemia patterns may be due to features of HCV infection or limitations of the assays used, rather than an indication of timing of transmission and that some infants who are

Table 2 Breastfed children with late first positive polymerase chain reactions (PCRs) ( $>4$ weeks) and non-breastfed children with late first positive PCRs and late last negative PCRs ( $>4$ weeks)

\begin{tabular}{lllll}
\hline Child & Breast fed & Age at last negative PCR & $\begin{array}{l}\text { Age at first positive } \\
\text { PCR (months) }\end{array}$ & $\begin{array}{l}\text { Age breast feeding } \\
\text { stopped (weeks) }\end{array}$ \\
\hline 1 & Yes & $\begin{array}{l}\text { 1 day (\& an indeterminate } \\
\text { PCR result at 4 weeks) }\end{array}$ & 4.7 & 20 \\
2 & Yes & 2 days & 3 & Not available \\
3 & Yes & Birth & 3 & Not available \\
4 & Yes & 3 days & 3 & Not available \\
5 & Yes & 2 days & 3 & Not available \\
6 & Yes & 24 days & 3.9 & 12 \\
7 & Yes & 2.7 months & 15 & \\
8 & No & 31 days & 2.2 & \\
9 & No & 32 days & 5.1 & \\
10 & No & 1.9 months & 5.8 & \\
11 & No & 5.6 months & 12.2 & \\
12 & No & 8.7 months & 13.4 & \\
\hline
\end{tabular}

For all these children, the first $\mathrm{PCR}$ test at $<3$ days was negative. 


\section{What is already known on this topic}

The overall rate of mother to child transmission of hepatitis $C$ virus ranges from $4 \%$ to $10 \%$ and is known to be associated with maternal HIV co-infection and HCV viraemia, but the timing of transmission-during pregnancy, at delivery, or postnatally-remains to be clarified.

infected intrapartum may not become PCR positive until after 4 weeks of age.

\section{Estimates of timing of infection}

Based on the timing of PCR tests, we can allocate the most likely time of transmission for all 54 children. Seventeen were PCR positive at $\leqslant 3$ days, giving an estimate of intrauterine transmission of $31 \%$ (95\% CI $19 \%$ to $46 \%$ ). Late intrauterine or intrapartum (at delivery) transmission is most likely for 27 (50\%, 95\% CI $36 \%$ to $64 \%$ ) who were PCR negative before 3 days but PCR positive when tested again by 3 months of age. Timing of transmission was more difficult to allocate for nine children $(17 \%)$ who were PCR negative at $\leqslant 3$ days and first PCR positive after 3 months. For three of these nine children, there was a long interval between the negative test at $\leqslant 3$ days and the next PCR test which was positive (child 1 in table 2 and two children who were not breast fed and first tested positive at 6 and 6.9 months). The other six children were PCR negative at $\leqslant 3$ days, negative again after 4 weeks, and not positive until after 3 months (children 6, 7, 9-12 in table 2), but only two of these six were breast fed, suggesting that peripartum transmission was most likely for all nine children. (Child 8 in table 2 is included among the 27 infants who were PCR positive by 3 months.) The remaining child (2\%) had no further PCR tests.

\section{DISCUSSION}

Our results suggest that at least one third (95\% CI 19\% to $46 \%$ ) of infants acquire HCV infection during the intrauterine period. Some children who tested PCR negative in the first 3 days of life may also have acquired infection in utero but with levels of viraemia that were undetectable by PCR. If transmission occurred late in pregnancy, viral replication could have been insufficient in the first few days to result in a positive PCR test, or HCV RNA production may have been delayed. Low plasma volumes from newborns may also give negative results in infants infected in utero. The 27 children who were PCR positive when tested for the second time by 3 months of age may fit the picture of late intrauterine transmission or intrapartum transmission, which would give an estimate of peripartum (late intrauterine and intrapartum) acquisition of infection of $36-64 \%$. The lower mean birth weight of children who were PCR positive in the first 3 days of life would be consistent with intrauterine transmission, although we lacked statistical power to detect a significant difference in the proportion of low birthweight infants between the two groups.

Resti et $_{\text {al }}{ }^{4}$ suggested that at least $46 \%$ (95\% CI 19\% to $75 \%$ ) of transmission occurred in utero, as six of 13 infected children had HCV RNA detected immediately after birth, in line with our findings. Gibb et $a l^{6}$ proposed that substantial intrapartum transmission of HCV occurred, but their results are difficult to interpret as infection status was inferred for many children. In over 1400 mother-child pairs from centres of the European Paediatric HCV Network, mode of delivery was not associated with risk of vertical transmission in women with only HCV infection. ${ }^{7}$ Several other smaller studies have failed to find a significant protective effect of elective caesarean section. ${ }^{3}{ }^{8}$ The lack of a protective effect of

\section{What this study adds}

Our results suggest that at least one third and up to a half of infected children acquired infection in utero. Although postpartum transmission through breast feeding cannot be excluded, these data would confirm that it is rare. Our results suggest that HCV genotype may influence the timing of transmission and this should be explored further.

elective caesarean section is consistent with a large proportion of intrauterine transmission. However, difficulties in interpreting early PCR results mean that conclusions reached about timing of transmission are not always consistent with evidence of the effect of mode of delivery. For example, although elective caesarean section is known to substantially reduce vertical transmission of HIV infection, time to first positive HIV DNA PCR test in infected children does not differ by mode of delivery. ${ }^{16}$

HCV has been detected in breast milk and colostrum, ${ }^{12}{ }^{13}$ and in one study the transmission rate was higher in babies exposed to HCV RNA positive breast milk. ${ }^{17}$ However, in most studies no association has been observed between transmission and mode of infant feeding. ${ }^{13}$ Of the seven breastfed children in our study with late first positive PCR tests, two were last PCR negative after 4 weeks of age, suggesting possible transmission through breast feeding. ${ }^{18}$ However, although we cannot exclude the possibility of postnatal transmission, the occurrence of late last negative and late first positive PCR tests in five of the non-breastfed children as well as in these two breastfed children suggests that these viraemia patterns may not necessarily indicate timing of transmission. We would echo the need to be cautious in inferring the timing of infection simply from early PCR results. ${ }^{19}$

Intermittent viraemia has been observed in a large proportion of children with vertically acquired HCV infection. ${ }^{20}$ This may reflect fluctuations in viral load which is undetectable at times, or low sensitivity of some PCR assays resulting in a negative test at low virus levels. Poor sensitivity of early assays may explain the late last negative PCR tests observed in seven children, but three of these children were born since 1999 when more sensitive assays were used. Intrapartum transmission would therefore be most likely for the nine children with first positive PCR tests after 3 months of age, increasing our estimate of peripartum transmission to $67 \%(36 / 54,95 \%$ CI $53 \%$ to $79 \%)$.

Although the assays used to detect HCV RNA vary between centres, the results of qualitative assays are generally consistent between laboratories. ${ }^{21}$ Only about one fifth of infected children enrolled in the European Paediatric HCV Network had a PCR result in the first 3 days of life. Although an early PCR test is recommended in the study protocol, there are several reasons why this was sometimes not done, including the high cost of PCR testing and the fact that some women were identified as HCV infected from a blood test taken at delivery with the result not available until four or five days later. However, the mother-child pairs included in this analysis were similar to the infected children who were not tested in the first 3 days of life with respect to the main variables of interest.

The limited number of children with early PCR results hinders clarification of factors influencing timing of transmission. Few studies have focused on the role of genotype as a risk factor for vertical transmission. In a study of 37 women, HCV subtypes $\mathrm{lb}$ and $3 \mathrm{a}$ were most commonly transmitted. ${ }^{22}$ Our results suggest that infants infected with genotype 1 were significantly more likely to have evidence of 
intrauterine infection than those with other genotypes. The reason for this is unclear, and further investigation is necessary.

Despite recent advances in our understanding of risk factors for mother to child transmission of HCV, the mechanisms and timing of transmission remain poorly understood. We have shown that at least one third of HCV transmission occurs in the intrauterine period, with around two thirds of infections likely to occur in the peripartum period, but, with the wide confidence intervals around our estimates, these percentages could be $50 \%$ and $50 \%$. Although the risk of postpartum transmission through breast feeding cannot be excluded, our results suggest that it is likely to be very low.

Maternal treatment to reduce the risk of vertical transmission, through lowering of viral load, is not currently possible, as interferon $\alpha$ and ribavirin are contraindicated during pregnancy. However, our results suggest that, if effective treatment were to become available, it would need to be initiated early in pregnancy, as at least one third of transmission occurs in utero.

\section{ACKNOWLEDGEMENTS}

We wish to thank the laboratory colleagues of the European Paediatric HCV Network collaborators and the women and children who participated in the study.

\section{Authors' affiliations}

J Mok, Paediatric HIV Service, Royal Hospital for Sick Children, 10 Chalmers Crescent, Edinburgh EH9 1TS, Scotland, UK

L Pembrey, M-L Newell, Centre for Paediatric Epidemiology and Biostatistics, Institute of Child Health \& Great Ormond Street Hospital for Children NHS Trust, University College London, 30 Guilford Street, London WCIN 1EH, UK

P-A Tovo, Dipartimento di Scienze Pediatriche e dell'Adolescenza, Università degli Studi di Torino, Piazza Polonia 94, 10126 Torino, Italy The European Paediatric HCV Network is funded by a European Commission concerted action grant-Quality of Life and Management of Living Resources Programme, contract number: QLK2-CT-2001-01165. L P is funded by a UK Medical Research Council Special Research Training Fellowship in Health Services and Health of the Public Research.

Competing interests: none declared

Appropriate ethical approval was obtained from each centre.

European Paediatric HCV Network collaborators: A Amoroso (Università di Trieste, Trieste, Italy), F Asensi-Botet, A Pereda (University Children's Hospital La Fè, Valencia, Spain), V Balossini, G Bona, M Zaffaroni (Clinica Pediatrica, Università del Piemonte Orientale, Novara, Italy), A Bandelloni, A Coscia, C Fabris (Cattedra di Neonatologia, Università di Torino, Torino, Italy), C Belloni (Neonatology and Neonatal Intensive Care Unit, IRCCS Policlinico San Matteo, Pavia, Italy), G Bossi, B Salati (Department of Pediatrics, IRCCS Policlinico San Matteo, Pavia, Italy), C Boucher (University Hospital Utrecht, Utrecht, The Netherlands), W Buffolano (Dipartimento di Pediatria, Università Federico II, Napoli, Italy), K Butler (Our Lady Hospital for Sick Children, Crumlin, Dublin, Ireland), L Cabero Roura, JM Bertran Sanges (Hospital Universitari Materno-Infantil, Barcelona, Spain), P Cigna (Centro di Neonatologia, Ospedale Infantile Regina Margherita, Torino, Italy), LM Ciria, C Servera Ginard (Hospital Son Dureta, Palma de Mallorca, Spain), G Claret Teruel, C Fortuny (Hospital Sant Joan de Déu, Barcelona, Spain), O Coll (Hospital Clinic, Barcelona, Spain), A Corrias, R Ledda, S Floris (Servizio di Puericultura, Cagliari, Italy), A De Maria (Dipartimento di Medicina Interna, Università di Genova, Genova, Italy), J Echeverria, G Cilla (Department of Paediatrics and Department of Microbiology, Hospital Donostia, San Sebastian, Spain), G Faldella, M Lanari, E Tridapalli, V Venturi, (Università di Bologna, Bologna, Italy), B Fischler, A-B Bohlin, S Lindgren, G Lindh (Huddinge Hospital, Huddinge, Sweden), V Giacomet, L Schneider, C Figini, L Caffarelli, A Viganò (Ospedale Sacco, Milano, Italy), S Hannam, G Mieli-Vergani (King's College Hospital, London, UK), A Hatzakis (National Retrovirus Reference Centre, University of Athens, Athens, Greece), C Inchley, HO Fjaerli (Akershus University Hospital, Norway), A Maccabruni (Department of Infectious Diseases, Università di Pavia, Pavia, Italy), M Marcellini, MR Sartorelli (Ospedale Bambino
Gesù, Roma, Italy), P Martin Fontelos (Servicio de Pediatria, Instituto de Salud Carlos III, Madrid, Spain), A Mazza (Ospedale Santa Chiara di Trento, Trento, Italy), JYQ Mok (Royal Hospital for Sick Children, Edinburgh), A Mûr, M Viñolas (Hospital del Mar, Universitat Autonoma de Barcelona, Spain), DM Paternoster, P Grella (Istituto di Ginecologia e Ostetricia, Padova, Italy), S Polywka (Institute for Medical Microbiology and Immunology, University Hospital Eppendorf, Hamburg, Germany), I Quinti, A M Casadei (Università La Sapienza, Roma, Italy), A Rojahn, A Berg (Ullevål University Hospital, Oslo, Norway), R Rosso, S Ferrando, D Bassetti (Clinica Malattie Infettive, Università di Genova, Genova, Italy), J Ruiz Contreras, A Manzanares (Hospital 12 de Octubre, Madrid, Spain), A Ruiz Extremera (Hospital Clinico San Ceciliò, Granada, Spain), F Salvini, G V Zuccotti, (Ospedale San Paolo, Milano, Italy), T Schmitz, I Grosch-Wörner, C Feiterna Sperling, T Piening (Charité Virchow-Klinikum, Berlin, Germany), H Souayah, J Levy (Hospital St Pierre, Brussels, Belgium), A Vegnente, R lorio (Dipartimento di Pediatria, Università Federico II, Napoli, Italy), A Versace, S Garetto, E Palomba, C Gabiano, L Balbo (Dipartimento di Pediatria, Università di Torino, Torino, Italy), R Wejstal, G Norkrans (Ostra Hospital, Goteborg, Sweden), A Zanetti, E Tanzi (Università di Milano, Milan, Italy)

\section{REFERENCES}

1 Tovo PA, Palomba E, Ferraris G, et al. Increased risk of maternal-infant hepatitis $C$ virus transmission for women co-infected with human immunodeficiency virus type 1. Italian Study Group for HCV infection in Children. Clin Infect Dis 1997:25:1121-4.

2 Zanetti AR, Tanzi E, Romano L, et al. A prospective study on mother-to-infant transmission of hepatitis C virus. Intervirology 1998;41:208-12.

3 Granovsky MO, Minkoff HL, Tess BH, et al. Hepatitis C virus infection in the mothers and infants cohort study. Pediatrics 1998;102:355-9.

4 Resti M, Azzari C, Mannelli F, et al. Mother-to-child transmission of hepatitis C virus: prospective study of risk factors and timing of infection in children born to women seronegative for HIV-1. BMJ 1998;317:437-41.

5 Thomas SL, Newell ML, Peckham CS, et al. A review of hepatitis C virus (HCV) vertical transmission: risks of transmission to infants born to mothers with and without HCV viraemia or human immunodeficiency virus infection. Int J Epidemiol 1998;27:108-17.

6 Gibb DM, Goodall RL, Dunn DT, et al. Mother-to-child transmission of Hepatitis $C$ virus: evidence for preventable peripartum transmission. Lancet 2000;356:904-7.

7 European Paediatric Hepatitis C Virus Network. Effects of mode of delivery and infant feeding on the risk of mother-to-child transmission of hepatitis $C$ virus. Br J Obstet Gynaecol 2001;108:371-7.

8 Thomas DL, Villano SA, Riester K, et al. Perinatal transmission of hepatitis C virus from human immunodeficiency virus type- 1 infected mothers. J Infect Dis 1998;177:1480-8.

9 Giacchino R, Tasso L, Timitilli A, et al. Vertical transmission of hepatitis C virus infection: Usefulness of viremia detection in HIV-seronegative hepatitis $\mathrm{C}$ viruspositive mothers. J Pediatr 1998;132:167-9.

10 Dal Molin G, D'Agaro P, Ansaldi F, et al. Mother-to-infant transmission of hepatitis $C$ virus: rate of infection and assessment of viral load and $\lg M$ antiHCV as risk factors. J Med Virol 2002;67:137-42.

11 Steininger C, Kundi M, Jatzko G, et al. Increased risk of mother-to-child transmission of hepatitis $C$ virus by intrapartum infantile exposure to maternal blood. J Infect Dis 2003; 187:345-51.

$12 \mathrm{Lin} \mathrm{HH}, \mathrm{Kao} \mathrm{JH}, \mathrm{Hsu} \mathrm{HY}$, et al. Absence of infection in breast-fed infants born to hepatitis C virus-infected mothers. J Pediatr 1995; 126:589-91.

13 Kumar RM, Shahul S. Role of breastfeeding in transmission of hepatitis $C$ virus to infants of HCV-infected mothers. J Hepatol 1998;29:191-7.

14 Weiner AJ, Thaler MM, Crawford K, et al. A unique, predominant hepatitis C virus found in an infant born to a mother with multiple variants. J Virol 1993;67:4365-8

15 Bryson YJ, Luzugiara K, Sullivan JL, et al. Proposed definitions for in utero versus intrapartum transmission of HIV-1. N Engl J Med 1992:327:1246-7.

16 Dunn DT, Brandt CD, Krivine A, et al. The sensitivity of HIV-1 DNA polymerase chain reaction in the neonatal period and the relative contributions of intra-uterine and intra-partum transmission. AIDS 1995:9:F7-11.

17 Ruiz-Extremera A, Salmeron J, Torres C, et al. Follow-up of transmission of hepatitis $C$ to babies of human immunodeficiency virus negative women: the role of breastfeeding in transmission. Pediatr Infect Dis J 2000;19:511-16.

18 Leroy V, Karon JM, Alioum A, et al, for the West Africa PMTCT Study Group. Postnatal transmission of HIV-1 after a maternal short-course zidovudine peripartum regimen in West Africa: a pooled analysis of two randomised clinical trials. AIDS 2003;17:1493-501

19 Dunn DT, Simonds RJ, Bulterys M, et al. Interventions to prevent vertical transmission of HIV-1: effect on viral detection rate in early infant samples. AIDS 2000;14:1421-8.

20 European Paediatric Hepatitis C Virus Infection Network. Persistence rate and progression of vertically acquired hepatitis $C$ infection. J Infect Dis 2000;181:419-24.

21 European Paediatric HCV Network. Inter-laboratory comparison of HCVRNA assay results: implications for multi-centre research. J Med Virol 2003;69:195-201.

22 Zuccotti GV, Ribero ML, Giovannini M, et al. Effect of hepatitis C genotype on mother-to-infant transmission of virus. J Pediatr 1995;127:278-80. 